\title{
Transurethral Resection of the Prostate at the Urology Department of Ignace Deen Hospital, Conakry, Guinea
}

\author{
Mamadou II Barry*, Amadou Camara, Thierno Mamadou Oury Diallo, Mamadou Bissiriou Bah, \\ Mamadou Diawo Bah, Lahoumbo Ricardo Gnammi, Thierno Oumar Diallo, Demba Cissé, \\ Daouda Kanté, Ibrahima Bah, Abdoulaye Bobo Diallo, Oumar Raphiou Bah
}

Urology Department of Ignace-Deen National Hospital/ Faculty of Health Sciences and Techniques, Gamal Abdel Nasser University of Conakry, Conakry, Guinea

\section{Email address: \\ barry2gn@yahoo.fr (M. II Barry) \\ ${ }^{*}$ Corresponding author}

\section{To cite this article:}

Mamadou II Barry, Amadou Camara, Thierno Mamadou Oury Diallo, Mamadou Bissiriou Bah, Mamadou Diawo Bah, Lahoumbo Ricardo Gnammi, Thierno Oumar Diallo, Demba Cissé, Daouda Kanté, Ibrahima Bah, Abdoulaye Bobo Diallo, Oumar Raphiou Bah. Transurethral Resection of the Prostate at the Urology Department of Ignace Deen Hospital, Conakry, Guinea. International Journal of Clinical Urology. Vol. 5, No. 1, 2021, pp. 25-29. doi: 10.11648/j.ijcu.20210501.16

Received: April 4, 2021; Accepted: April 22, 2021; Published: April 30, 2021

\begin{abstract}
Transurethral resection of the prostate (TURP) remains the gold standard treatment for benign prostatic hyperplasia (BPH). Objective: To report the results of TURP to the Urology Department of Ignace Deen National hospital Patients and methods: This was a prospective, descriptive study of 2 years 5 months (January 1, 2015 to May 31, 2017), carried out in the urology department of the Ignace Deen National Hospital. We included 86 patients who benefited from an isolated TURP or associated with another surgical procedure. Results: TURP accounted for $51.19 \%$ of endoscopic surgery and $20.18 \%$ of prostate surgery. The mean age was 69.21 years (48 and 89 ). The mean total PSA level was $17.7 \mathrm{ng} / \mathrm{ml}$. The mean prostate volume was $54,22 \mathrm{~cm}^{3}$ (27 and 107). The indication for surgery was dominated by chronic retention of bladder urine (93.02\%). The mean duration of TURP was $41.84 \mathrm{~min}$ (28 and 58). Postoperative complications were dominated by orchi-epididymitis $(5.81 \%)$ and UVR $(4.66 \%)$. The mean length of stay was 5.63 days. The histologic types were: benign prostatic hyperplasia (69.77\%), prostatic adenocarcinoma (29.07\%) and high grade intraepithelial prostate neoplasia $(1.16 \%)$. After a mean followup of 2.21 months, the result was good in $95.35 \%$ of cases. Conclusion: It offers low morbidity and a good result in almost all cases.
\end{abstract}

Keywords: Transurethral Resection of the Prostate, Ignace Deen Hospital, Conakry, Guinea

\section{Introduction}

Since the description of the first transurethral resection of the prostate (TURP) in 1901, the development of the technique has made it the gold standard treatment for benign prostatic hyperplasia (BPH) [1]. In developed countries since many decades, TURP has become the gold standard in the surgical treatment of obstructive BPH with a prostate volume between $30-80 \mathrm{ml}$ [2]. However, two major complications are recognized from monopolar TURP, notably compartment hemorrhage and TURP syndrome. To limit these complications and promote resections of prostatic volume of more than $80 \mathrm{ml}$, we have seen the birth of bipolar TURP then new so-called "minimally invasive" techniques, in particular vaporization with Greenlight or enucleation with Holmium Laser.

In Africa, prostatic adenomectomy takes precedence over endoscopic surgery in the surgical treatment of benign prostatic hypertrophy.

In Guinea, TURP was created in 1987 as part of a support cooperation from the University of Liège, Belgium. A study carried out in the service by Guirassy et al. [3] between 1996 and 2001 had collected 550 cases of endoscopic surgery in which TURP accounted for $18.9 \%$ of surgery on the prostate. For almost a decade and a half, the aim of the study was to describe the results and morbidity and mortality of this technique in our department. 


\section{Material and Method}

This was a prospective descriptive study over 2 years 5 months from January 2, 2015 to May 31, 2017 carried out at the urology andrology department of the Ignace Deen National Hospital, Conakry University Hospital. It focused on all patients who received TURP during this period whether performed for BPH or prostate cancer as part of a clearing of obstruction. To carry out the study, a survey sheet was designed. The resection material was a monopolar resector with a 26 charrière sheath and a $30^{\circ}$ optic. The irrigation fluid was Glycocolle.

The study variables were the proportion of TURP in endoscopic surgery and in prostate surgery, age of patients, digital rectal examination, prostate specific antigen (PSA) level, indication of resection, the duration of the resection, the associated procedures, the per- and post-operative complications, the duration of the drainage and the study of urination.

The evaluation of TURP outcomes was clinical based on the study of urination and urinary continence. This assessment was done when the catheter was removed before the patient was discharged from the hospital and then at one week, one month, three months and six months. The results were judged:

1) good: when the urination was normal with good bladder continence, that is to say the voiding jet was satisfying for the patient in the absence of dysuria and urine leakage between urination or if these complaints give way before the urination. end of the 1 st month;

2) Average: in the event of dysuria or acute retention of urine after removal of the catheter requiring replacement of the catheter for 5 to 7 days with the reestablishment of normal urination thereafter, or also in the event of urine leakage which disappears before the 3rd month of the operation.

3) Bad: persistence of dysuria, episodes of acute retention of urine, or urinary incontinence beyond the $3 \mathrm{rd}$ month.

\section{Results}

During the study period, 168 acts of endoscopic surgery were performed among which TURP took first place with $51.19 \%(\mathrm{n}=86)$ followed by endoscopic internal urethrotomy (UIE), 426 surgeries on the prostate including 86 cases of TURP or $20.18 \%$.

The average age was 69.21 years with extremes of 48 and 89 years. The most affected age groups were those of 60-69 and $70-79$ with respectively $31.40 \%(\mathrm{n}=27)$ and $29.07 \%(\mathrm{n}$ $=25$ ).

The mean PSA level was $17.7 \mathrm{ng} / \mathrm{ml}$ with extremes of $0.46 \mathrm{ng} / \mathrm{ml}$ and $176 \mathrm{ng} / \mathrm{ml}$. Almost $63 \%(\mathrm{n}=54)$ of patients had a PSA between 0 and $10 \mathrm{ng} / \mathrm{ml}$.

A urinary tract infection was found in 38 patients (44.20\%). Escherichia coli and Staphylococcus aureus were isolated from 27 and 11 patients, respectively. Hyperglycemia was observed in 5 patients, anemia (Hb level: $10-11 \mathrm{~g} / \mathrm{dl}$ ) in 2 patients and in 2 other patients serum creatinine ranged from 120 - $137 \mathrm{micromol} / 1$.

The mean prostate volume was $54.22 \mathrm{~cm}^{3}$ with extremes of 27 and $107 \mathrm{~cm}^{3}$. This volume was less than $30 \mathrm{~cm}^{3}$ in 44 patients and between 30 and $60 \mathrm{~cm}^{3}$ in 35 patients.

The indications for surgery were varied. In 16 patients, resection was performed as part of a clearance for prostate cancer with chronic retention of urine. Resection was indicated for BPH complicated by chronic retention of urine in $74.42 \%(n=64)$, acute retention of repeated urine in $3.48 \%$ $(\mathrm{n}=3)$ or failure of drug treatment of BPH in 3 patients.

Spinal anesthesia was used in $97.67 \%$ of cases $(n=84)$ and general anesthesia in $2.33 \%$ of cases $(n=2)$. TURP was associated with surgery in $22.09 \%$ of cases $(n=19)$ including pulpectomy in 12 patients $(13.95 \%)$, Endoscopic internal urethrotomy (EIU) in 5 patients $(5.81 \%)$ and inguinal hernia repair in 2 patients.

The mean duration of TURP was 41.84 minutes with extremes of 28 and 58 minutes. This intervention time was increased from 15 to 46 min depending on whether TURP was associated with EIU or inguinal herniorrhaphy.

The mean duration of postoperative bladder drainage was 5.32 days with extremes of 3 and 7 days. The mean length of stay was 6.22 days with extremes of 4 and 8 days.

The postoperative consequences were simple in $88.37 \%$ (n $=76$ ). We noted early postoperative complications in $11.62 \%$ $(\mathrm{n}=10)$ of cases including orchi-epididymitis in $5.81 \%(\mathrm{n}=$ $5)$, urinary bladder retention in $4.65 \%(\mathrm{n}=4)$ and hematuria due to pressure ulcer fall: $1.16 \%(\mathrm{n}=1)$.

Pathological examination of the resection shavings found prostatic adenomyoma in 60 patients $(69.77 \%)$, prostatic adenocarcinoma in 25 patients $(29.07 \%)$ and high-grade PIN in one patient. Among the 25 cases of prostatic adenocarcinoma, 16 had a preoperative diagnosis on ultrasound guided prostate biopsy.

After a mean follow-up of 3.21 months with extremes of 1 and 6 months, TURP results were good in 82 patients $(95.35 \%)$ and average in 4 patients.

\section{Discussion}

During the past six decades, TURP has been the gold standard in the surgical treatment of BPH in developed countries [4, 5, 6]. In sub-Saharan Africa, adenomectomy still takes precedence over TURP even though the latter offers the same long-term functional results with less morbidity. The use of TURP in the surgical treatment of BPH $(20.19 \%)$ is slightly improved in our department compared to the study by Guirassy [3] where its frequency was $18.9 \%$. The frequency of TURP remains low in West African countries as shown by the study by Zango [7] from Burkina Faso (8.11\%), from Kane [8] to Dakar (29.05\%). However, hope is allowed thanks to the arrival of bipolar in our country and in the subregion as evidenced by the preliminary results of Diakité et al. [9] in Bamako with 322 patients having benefited from a TURP representing $57.7 \%$ of endoscopic procedures and the application center for the Inter-University Diploma (DIU) of 
Endo-Urology in Dakar.

The incidence of BPH increases with age. The average age of our patients was 69.21 years with extremes of 48 and 89 years. This mean age is close to that reported by certain authors $[4,8,10]$ (Table 1). A younger mean age (63.6 \pm 4.2 with extremes of 54 and 71) has been reported by Abd-El Kader et al. [11].

Table 1. Comparative study of variables with those of orther authors.

\begin{tabular}{|c|c|c|c|c|c|}
\hline Variables & Our series & Kane [8] & Ghozzi [10] & Kong [14] & Reich [4] \\
\hline Effective & 86 & 86 & 29 & 51 & 9197 \\
\hline Age & $69,21(48-89)$ & $70,3(49-82)$ & $68,71 \pm 7,63$ & 68,53 & 71,1 \\
\hline IPSS & - & - & $23,89 \pm 2,16$ & $23,9 \pm 4,32$ & $20,5 \pm 7,6$ \\
\hline Preoperative urine retention & 95,71 & 38,67 & & & 27,7 \\
\hline PSA moyen ng/ml & $17,7(0,46-100)$ & $25(5-557)$ & $2,9 \pm 0,88$ & & - \\
\hline V.P. moyen & $54,42(27-107)$ & $51,6(24-90)$ & $49,5 \pm 5,80$ & $43,1 \pm 10,94$ & $44,4 \pm 27,0$ \\
\hline Average duration (mn) & $41,8(28-58)$ & $52(34-58)$ & 50 & & $52,4 \pm 26,4$ \\
\hline DMS (day) & $6,22(4-8)$ & 5 & $2,9 \pm 0,89$ & $2,6 \pm 0,92$ & $8 \pm 6,1$ \\
\hline Complication rate & 11,62 & 11,62 & 20,68 & & 11,1 \\
\hline Bleeding $\%$ & 1,16 & 1,2 & & & \\
\hline Transfusion $\%$ & - & & 6,89 & 1,96 & 2,9 \\
\hline TURP syndrome $\%$ & - & 1,2 & 6,89 & & 1,4 \\
\hline Urine retention $\%$ & 4,65 & 3,4 & 6,89 & 3,92 & 5,8 \\
\hline Orchiepididymitis $\%$ & 5,81 & - & - & & 3,6 \\
\hline
\end{tabular}

$\mathrm{PV}=$ Prostate Volume, $\mathrm{POP}=$ post-operative, $\mathrm{ALS}=$ Average length of stay

The International Prostate Symptom Score (IPSS), evaluated by several authors (see Table 1) as recommended by learned societies (Committee of micturition disorders of the French Association of Urology, the European Association of Urology) has not been evaluated in our series by the fact that out of 70 cases of $\mathrm{BPH}, 67$ patients $(95.71 \%)$ were admitted in a picture of chronic retention of urine (64 cases) or acute retention of urine (3 cases). Abdallah et al. [12] reported that $30 \%$ of their patients presented with urine retention. Kouamé et al. [13] reported 56.6\% $(\mathrm{n}=53)$ of urinary bladder retention. This difference could be explained by the late consultation time for our patients.

The average PSA level $(17.7 \mathrm{ng} / \mathrm{ml})$ in our series is close to that of Diakité et al. [9] which reported $15 \mathrm{ng} / \mathrm{ml}$ (range 4 and 250ng / $\mathrm{ml}$ ). Kane et al. [8] reported an average PSA of $25 \mathrm{ng} / \mathrm{ml}$ with extremes of 5 and $557 \mathrm{ng} / \mathrm{ml}$. However, it remains relatively higher compared to the study by Ghozzi et al. [10], where it was $2.9 \mathrm{ng} / \mathrm{ml} \pm 0.88$. The high PSA level in our series as well as those of Kane and Diakité was due to the fact that TURP affected both BPH and locally advanced or metastatic prostate cancer (16 cases in our study). Several authors [4, 14-16] have not reported a PSA level. The PSA assay is part of the recommended work-up in the surgical management of BPH in patients where the discovery of prostate cancer could change the therapeutic indication.

Prostate volume is an important parameter in the choice of endoscopic technique. Monopolar TURP is considered the gold standard for patients with prostate volume greater than $30 \mathrm{~mL}$ and less than $60-80 \mathrm{~mL}$ [1]. Randomized studies comparing monopolar TURP to cervico-prostatic incision (PCI) did not show a significant difference in terms of functional outcome in patients with a small prostate $(<20-30$ $\mathrm{mL}$ ) and without a lobe median. The advantages of PCI are reduced operating time, the risk of bleeding, the length of hospital stay and the risk of retrograde ejaculation. However, the risk of symptom recurrence and repeated surgery is higher [1]. This PCI could have been used for 44 of our patients who had a prostate volume less than $30 \mathrm{ml}$.

The ECBU must be sterile. Intraoperative antibiotic prophylaxis is recommended, as it significantly reduces the risk of postoperative bacteremia [1]. A urinary tract infection was treated according to the antibiogram in 38 of our patients (44.20\%) before TURP.

A urinary tract infection was treated with the antibiogram preoperatively in $17.08 \%(n=55)$ of the patients of Diakité et al. [9].

The mean duration of TURP was 41.84 minutes with extremes of 28 and 58 minutes. This intervention time was increased from 15 to $46 \mathrm{~min}$ depending on whether TURP was associated with UIE, pulpectomy or inguinal herniorrhaphy. Kane et al. [8] reported an average duration of TURP of 52 min with extremes of 34 and $58 \mathrm{~min}$. For Ghozzi et al. [10], the average duration of a mono-polar TURP was 50 minutes versus 40.5 minutes in bipolar. This difference in the mean duration of mono-polar TURP could be explained by the selective nature of the prostate volumes to be resected (44 patients out of 70 cases of BPH had a prostate volume of less than $30 \mathrm{ml}$ ) and the endoscopic experience of the surgeon.

TURP dramatically reduces the duration of postoperative drainage and the length of hospital stay. This drainage duration is shorter in the more recent series $[10,14]$ (Table 1) where it is on average less than 66 hours and consequently a hospital stay of less than 72 hours. Méndez-Probst et al. [5], did not find a significant difference in the duration of postoperative drainage ( 1.5 vs. 1.1 days $)$ and the mean duration of hospitalization (1.1 [range: $0-3$ ] vs. 1.0 [range: 0 2] days) for bipolar TURP and mono-polar TURP, respectively.

Monopolar TURP remains the gold standard in the surgical management of $\mathrm{BPH}[5,10]$. Admittedly, it is a technique that has proven its effectiveness in the long term, 
nevertheless, it remains associated with a certain number of challenges, in particular the occurrence of potentially serious complications in the perioperative period, to which we add the limits of this technique, particularly those related to the field. of the sick [10]. This has certainly prompted the use of new technologies considered minimally invasive and less likely to cause morbidity and complications than monopolar TURP. Among these techniques is bipolar TURP which has the advantage of reproducing the same conditions as classical resection [10]. Several studies have compared monopolar TURP to bipolar TURP [17-20] or monopolar TURP with Bipolar prostatic vaporization [21] or Greenlight [22] or prostatic enucleation with Holmium Laser (HoLEP) [23].

The most well-known intraoperative complications of monopolar TURP include: bleeding which may require transfusion, resumption syndrome and urine retention by clot or incomplete resection.

The incidence of bleeding after monopolar TURP requiring transfusion varies between 0.4 and $7.1 \%$ [10, 14, 24, 25] versus zero transfusion during bipolar prostatic vaporization [25]. We did not note any bleeding complications requiring transfusion as shown in Table 1. Over time this bleeding complication has greatly improved thanks to the experience acquired by urologists. This was demonstrated by a 30 -year retrospective mono-center study which reported a rate of $44 \%$ of patients requiring blood transfusion after TURP in the 1970 s compared to a rate of $11 \%$ in the 1980 s and $4 \%$ in 1990 s.

The use of glycocolle contributes to the occurrence of TURP syndrome. This risk is also increased from $0.7 \%$ to $2 \%$ if the resection lasts more than 90 minutes and the weight of the resected prostate $>45 \mathrm{~g}$ [14]. Pasha et al. [26] comparing the use of glycine or sterile distilled water for irrigation during TURP reported a rate of TURP syndrome of $15.3 \%$ and $11.8 \%$ respectively. In our series, the use of glycocolle as an irrigation solution, the small volume of prostate to be resected and the experience gained over the past 2 decades have probably contributed to reducing or even eliminating this complication. In 2001, Guirassy in the same department had reported $0.74 \%$ of TURP syndrome [3]. The risk of "TURP syndrome" has decreased for ten years; it is currently evaluated at $0.1 \%[1,23]$.

Urinary retention upon removal of the urethral catheter occurs in 3 to $9 \%$ of cases, the most common cause being detrusor hypoactivity [1, 23]. An indwelling bladder catheterization for two to four weeks can most often allow a spontaneous resumption of urination. Repeated TURP should therefore not be considered less than six weeks after the first TURP [1]. The urine retention rate of $4.65 \%$ in our series is within the range of the literature (Table 1 ).

The rate of orchiepididymitis in our series would probably be favored by the number of patients with catheters before the operation, the quality of the irrigation solution and the length of postoperative catheter wear.

\section{Conclusion}

TURP remains the gold standard treatment for complicated obstructive prostatic hyperplasia or after failure of drug treatment for the symptoms of the lower urinary tract for which it is responsible. Its indication is slightly improving in the light of a study carried out in 2001 in our department. However, the experience gained has reduced the complication rate of TURP. The hope of seeing its indications broaden is allowed thanks to the installation of mono and bipolar columns in our country and the proximity to the IUD application center for endo-urology in Dakar.

The study of the outcomes and morbidity of transurethral resection of the prostate could be continued with a prospective study comparing the monopolar and bipolar techniques.

\section{Conflict of Interest Statement}

The authors declare that they have no competing interests.

\section{References}

[1] Delongchamps N-B, Robert G, Descazeaud A, Cornu J-N, Azzouzi A-R, Haillot O, et al. Traitement de l'hyperplasie bénigne de prostate par techniques endoscopiques électriques et adénomectomie voie haute : revue de littérature du CTMH de l'AFU. Prog Urol. 2012; 22 (2): 73-79.

[2] Zheng X, Han X, Cao D, Wang Y, Xu H, Yang L, et al. Comparison of Short-Term Outcomes between Button-Type Bipolar Plasma Vaporization and Transurethral Resection for the Prostate: A Systematic Review and Meta-Analysis. Int J Med Sci. 2019; 16 (12): 1564-1572.

[3] Guirassy S. La chirurgie endoscopique du bas appareil urinaire au C. H. U. Ignace Deen à propos de 550 cas. African Journal of Urology 1110-5704 .2006, 12 (2): 96-100

[4] Reich O, Gratzke C, Bachmann A, Seitz M, Schlenker B, Hermanek P, et al. Morbidity, Mortality and Early Outcome of Transurethral Resection of the Prostate: A Prospective Multicenter Evaluation of 10,654 Patients. Journal of Urology. 2008; 180 (1): 246-249. DOI: 10.1016/j.juro.2008.03.058.

[5] Méndez-Probst CE, Nott L, Pautler SE, Razvi H. A multicentre single-blind randomized controlled trial comparing bipolar and monopolar transurethral resection of the prostate. Can Urol Assoc J 2011;5(6):385-9; http://dx.doi.org/10.5489/cuaj.10199

[6] Larouche A, Becker A, Schiffmann J, Roghmann F, Gandaglia $\mathrm{G}$, Hanna N, et al. Comparison between complication rates of laser prostatectomy electrocautery transurethral resection of the prostate: A population-based study. Can Urol Assoc J 2014;8(5-6):e419-24. http://dx.doi.org/10.5489/cuaj.1790

[7] Zango B, Kambou T, Sanou A. La Résection transurétrale de la prostate à l'hôpital Sanou Souro de Bobo-Dioulasso: à propos de 68 cas. African Journal of Urology 1110-5704. 2002, $8(1): 1-5$.

[8] Kane R, Ndiaye A, Ogougbemy M. Resection transuretrale de prostate. Medecine d'Afrique Noire. 2013, 60 (3): 110-114. 
[9] Diakité M. L, Berthé H. J. G, Diallo M. S, Kambou D, Banou P, Diakité A. S, Sangaré D, Sissoko I, Tembely A. La Résection endoscopique bipolaire: Expérience du service d'urologie CHU du Point G. Uro'Andro -2016, 1 (6):264-268.

[10] Ghozzi S, Ghorbel J, Ben Ali M, Dridi M, Maarouf J, Khiari R, et al. Résection transuréthrale de la prostate bipolaire versus monopolaire : étude prospective randomisée. Prog Urol. 2014; 24 (2): 121-126.

[11] Abd-El Kader O, Mohy El Den K, El Nashar A, Hussein A, Yehya E. Transurethral incision versus transurethral resection of the prostate in small prostatic adenoma: Long-term followup. African Journal of Urology. 2012; 18 (1): 29-33.

[12] Abdallah MM, Badreldin MO. A short-term evaluation of the safety and the efficacy of bipolar transurethral resection of the prostate in patients with a large prostate $(>90 \mathrm{~g})$. Arab Journal of Urology. 2014; 12 (4): 251-255. DOI: 10.1016/j.aju.2014.10.003.

[13] Kouamé B, Ndoye M, Koumoumoritoua R. D., Mahamat A., Jallohm, Migue K., Amadou R. M., Yacine W., Labou I., Diaw J., Mane L., et al. Résection trans urétrale de la prostate (RTUP) : indications et résultats à l'Hôpital Général de Grand Yoff : à propos de 145 cas. Revue Algérienne d'Urologie Déc 2017, N 9: 61-66.

[14] Kong CHC, Ibrahim MF, Zainuddin Z. A prospective, randomized clinical trial comparing bipolar plasma kinetic resection of the prostate versus conventional monopolar transurethral resection of the prostate in the treatment of benign prostatic hyperplasia. Ann Saudi Med. 2009; 4 Ann Saudi Med 29 (6): 429-432.

[15] Türk H, Ün S, Arslan E. A new surgical technique: transvesical resection of prostate - case series. Int braz $\mathrm{j}$ urol. 2018; 44 (5): 1023-1031.

[16] Cury J, Coelho RF, Bruschini H, Srougi M. Is the ability to perform transurethral resection of the prostate influenced by the surgeon's previous experience? Clinics. 2008; 63 (3): 315320 .

[17] Yang EJ, Li H, Sun XB, Huang L, Wang L, Gong XX, et al. Bipolar versus monopolar transurethral resection of the prostate for benign prostatic hyperplasia: safe in patients with high surgical risk. Sci Rep. 2016; 6 (1): 1-5. DOI: $10.1038 /$ srep21494.

[18] Michielsen DPJ, Coomans D, Lersberghe CV, Braeckman JG.
Comparison of the haemostatic properties of conventional monopolar and bipolar transurethral resection of the prostate in patients on oral anticoagulants. Arch Med Sci 5, October/ 2011; 5: 858-863. DOI: 10.5114/aoms.2011.25562.

[19] Kim JH, Park JY, Shim JS, Lee JG, Moon DG, Yoo JW, Choi $\mathrm{H}$, et al. Comparison of outpatient versus inpatient transurethral prostate resection for benign prostatic hyperplasia: Comparative, prospective bi-center study. Can Urol Assoc J 2014; 8 (1-2): e30-5. http://dx.doi.org/10.5489/cuaj.1370.

[20] Karadeniz MS, Bayazit E, Aksoy O, Salviz EA, Tefik T, Sanli $\mathrm{O}$, et al. Bipolar versus monopolar resection of benign prostate hyperplasia: a comparison of plasma electrolytes, hemoglobin and TUR syndrome. SpringerPlus. 2016; 5 (1): 1739-1746.

[21] Moldoveanu C, Geavlete B, Jecu M, Stanescu F, Adou L, Bulai C, Ene C, Geavlete P. Bipolar plasma vaporization versus monopolar TUR and "cold-knife" TUI in secondary bladder neck sclerosis - An evidence based, retrospective critical comparison in a single center clinical setting. Journal of Medicine and Life Vol. 7, Issue 1, January-March 2014: 9499.

[22] Lai S, Peng P, Diao T, Hou H, Wang X, Zhang W, et al. Comparison of photoselective green light laser vaporisation versus traditional transurethral resection for benign prostate hyperplasia: an updated systematic review and meta-analysis of randomised controlled trials and prospective studies. BMJ Open 2019; 9: e028855-68. doi: 10.1136/bmjopen-2018028855 .

[23] Robert G, de la Taille A, Descazeaud A. Traitements chirurgicaux de l'obstruction prostatique bénigne : standards et innovations. Prog Urol. 2018; 28 (15): 856-867.

[24] Teo JS, Lee YM, Ho HSS. An update on transurethral surgery for benign prostatic obstruction. Asian Journal of Urology. 2017; 4 (3): 195-198.

[25] Elsakka AM, Eltatawy HH, Almekaty KH, Ramadan AR, Gameel TA, Farahat Y. A prospective randomised controlled study comparing bipolar plasma vaporisation of the prostate to monopolar transurethral resection of the prostate. Arab Journal of Urology. 2016; 14 (4): 280-286.

[26] Pasha MT, Khan MA, Jamal Y, Wahab F, Ashraf H. Postoperative complications with glycine and sterile distilled water after transurethral resection of prostate. J Ayub Med Coll Abbottabad 2015; 27 (1): 135-139. 